\title{
Speech Sounds and the Production of Droplets and Aerosols
}

\author{
Satoshi Hamada ${ }^{1}$, Naoya Tanabe $^{2}$ and Toyohiro Hirai ${ }^{2}$
}

Key words: mask, particle, plosive, visualization

(Intern Med 60: 1649-1650, 2021)

(DOI: 10.2169/internalmedicine.5888-20)

(A)
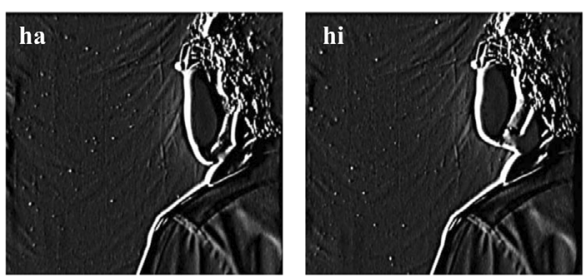

(B)
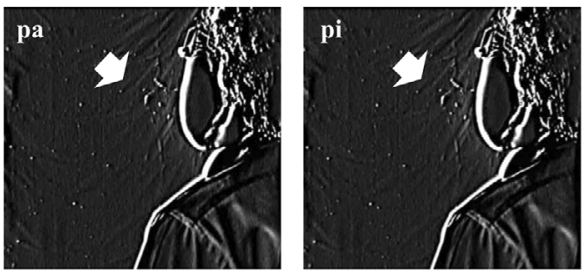

(C)
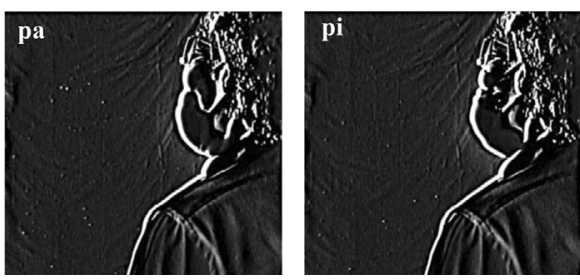
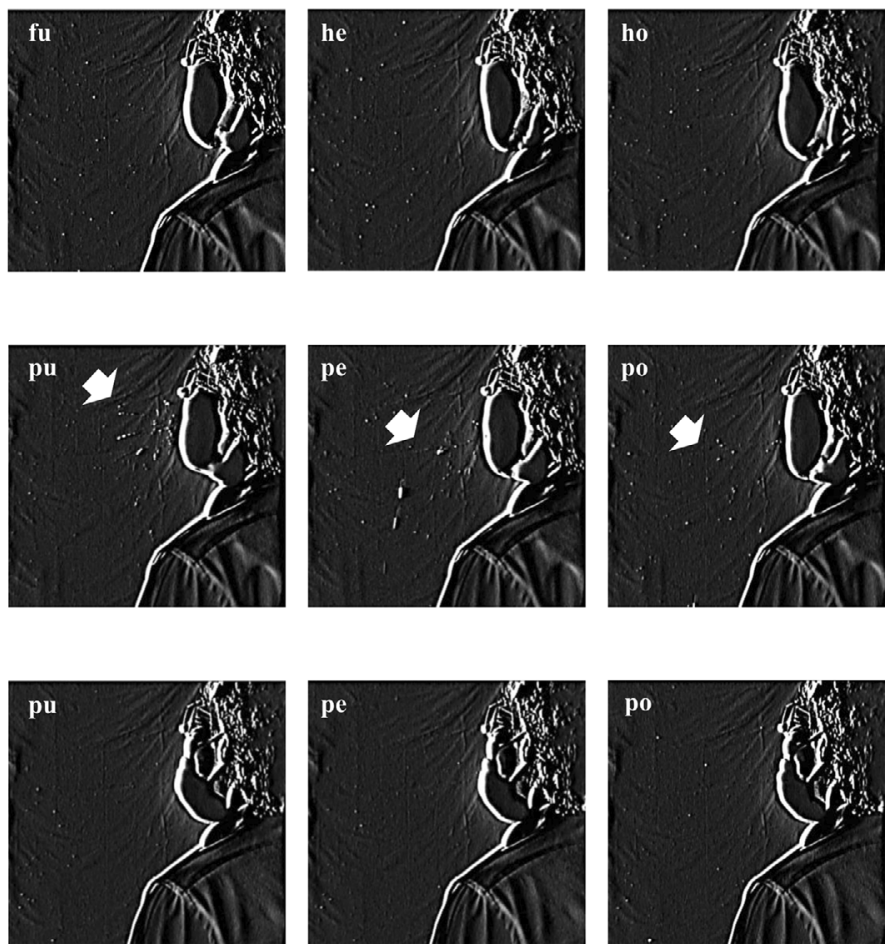

Picture.

The person-to-person transmission of severe acute respiratory syndrome (SARS)-coronavirus-2 has focused on particle production via talking, which may depend on the characteristics of speech sounds, such as plosives and fricatives. We visualized particle dispersion while vocalizing monosyllabic words using a particle visualization system (Shin Nippon Air Technologies, Tokyo, Japan), which allowed the visualization of particles $\geq 1 \mu \mathrm{m}$ in diameter (1). Although we identified no apparent particles during ha, hi, fu, he, and ho (fricatives) vocalization without a mask (Picture A), particles were dispersed during pa, pi, pu, pe, and po (plosives) vocalization without a mask (Picture B). When wearing a surgical mask, no apparent particles were detected even during plosive vocalization (Picture C). As distributions of speech sounds differ among languages, our findings support the notion that the differences in quantity of particle production among languages may influence the differences in SARS morbidity among countries (2), information that can be used to encourage people to wear masks.

The authors state that they have no Conflict of Interest (COI).

\section{Financial Support}

This study was funded in part by the JSPS KAKENHI 19K

\footnotetext{
${ }^{1}$ Department of Advanced Medicine for Respiratory Failure, Graduate School of Medicine, Kyoto University, Japan and ${ }^{2}$ Department of Respiratory Medicine, Graduate School of Medicine, Kyoto University, Japan

Received: July 19, 2020; Accepted: September 6, 2020; Advance Publication by J-STAGE: December 15, 2020

Correspondence to Dr. Naoya Tanabe, ntana@kuhp.kyoto-u.ac.jp
} 
17634 (SH).

The Department of Advanced Medicine for Respiratory Failure is a Department of Collaborative Research Laboratory funded by Teijin Pharma.

\section{Acknowledgement}

The authors are grateful to Mr. Ryuta Okamoto, Mr. Taro Furukawa, and Mr. Kozo Takahashi for their technical assistance.

\section{References}

1. Ogawa Y, Mizutani M, Okamoto R, Kitajima H, Ezoe S,
Kino-Oka M. Understanding the formation and behaviors of droplets toward consideration of changeover during cell manufacturing. Regen Ther 12: 36-42, 2019.

2. Inouye S. SARS transmission: language and droplet production. Lancet 362: 170, 2003.

The Internal Medicine is an Open Access journal distributed under the Creative Commons Attribution-NonCommercial-NoDerivatives 4.0 International License. To view the details of this license, please visit (https://creativecommons.org/licenses/ by-nc-nd/4.0/).

(C) 2021 The Japanese Society of Internal Medicine Intern Med 60: 1649-1650, 2021 